\title{
Royal Society of Medicine
}

Nowadays the man who had had the operation wore nothing except, perhaps, a tracheotomy tube, yet could speak intelligibly. This represented a very great advance.

Dr DOUgLas GUTHRIE (in reply) said that the patient was a smoker; he resumed smoking early in his convalescence. The air was not consciously swallowed nor was the patient aware that he contracted his abdominal muscles. He seemed to produce his voice by dilating his œsophagus, as described by $\mathrm{Mr}$ O'Malley, and certainly the abdominal muscles were not tightened by conscious effort. He recovered a little use of his voice within a month of the operation, and when he left two months after operation he was able to make himself intelligible to the nurses. Of course, there was still room for improvement. He never had any lessons in voice-production, but evolved his own method. In answer to Dr Paterson's remarks about bagpipes, the man himself said that only a Scotsman could have recovered, and recovered with such a voice.

Case of (?) Mucocele - Anthony M'CaLl, M.D. - Female, aged 20, was seen at hospital, November r924, with a swelling in the neighbourhood of the left supra-orbital notch, which had been present for three years : No pain or nasal discharge at any time.

Extensive necrotic changes were found at operation in the anterior wall of the frontal sinus extending into the ethmoid and sphenoid sinus. Only a blunt spoon and gauze used; external wound closed and drained by tube through nose; keloid scar treated by cautery; no discharge for eighteen months.

\section{ABSTRACTS}

\section{THE EAR.}

A Theory of Caloric Nystagmus. G. V. Borries, Copenhagen. (Zeitschrift für Laryngologie, Rhinologie, etc., April 1926, pp. 253-2 55.)

This is a brief restatement of the author's views which were given in full in the Acta Oto-Laryngologica, Bds. ii. and iv. The chief points are:-

(I) Caloric nystagmus can be produced even after destruction of the semicircular canals ; this was demonstrated experimentally in pigeons. The author believes that caloric nystagmusin contra-distinction to rotatory nystagmus-may be a pure otolith reaction.

(2) The alteration in the direction of the caloric nystagmus, according to various head positions, is probably also an otolith reaction. At any rate Bárány's theory of endolymph movements cannot explain these variations when the position of the head is altered.

J. KEEN. 


\section{Abstracts \\ Disturbances of the Function of the Otoliths in Ear Diseases. \\ G. Tenaglia. (Arch. Ital. di Otol., May 1925.)}

The author has examined systematically a large number of cases of disease of the ear of various kinds in several clinics, with special reference to disturbances of the function of the otoliths. $\mathrm{He}$ has followed the method of Quix, whose theory postulates that pressure of the otolith on one of the maculæ increases the tone of certain muscles.

His tests for irritation of the maculæ consist of pointing tests in a horizontal direction with the head in the normal position or inclined forward thirty degrees or backwards seventy-five degrees. To test the macula sacculi he carried out pointing tests in the vertical plane with the head in the normal position or tilted over to one or other side.

He cites a number of cases in which there were alterations in these tests and concludes :

(1) The disturbances of the function of the otoliths are evident in acute diseases of the ear, but more especially in chronic disease with exacerbation, whether these are inflammatory or traumatic or toxic. They last as long as the acute irritation remains.

(2) They are more evident in connection with the otolith of the saccule than with that of the utricle, those of the former being accompanied rather by disturbances of hearing and the latter by symptoms of irritation of the semicircular canals.

(3) Operation on the ear and cure of the suppuration removes the symptoms, and the author thinks that the deviations in the pointing tests must be due to vestibular reflexes.

(4) Examination by means of pointing with the index finger in the horizontal plane for the macula sacculi is a useful method of examining the inner ear.

J. K. M. DickiE.

Slow Nystagmus. G. Borries, Copenhagen. (Zeitschrift für Hals-, Nasen-, und Ohrenheilkunde, Bd. xiii., Heft 3, p. $3^{18 .)}$

Borries discusses some cases in which the induced nystagmus, rotational or caloric, was extraordinarily slow; the nystagmus was chiefly horizontal and induced by rotation. In general, he looks upon it as an indication of weakness of reaction and he only considers it in relation to the quick phase of the nystagmus. In some cases slow post-rotatory nystagmus is present along with normal caloric. He rejects any idea of the reflex paths for the quick, as also for the slow phase, being supplied by the cerebrum; therefore, some other explanation is required. In one of his cases, in which the disease was undoubtedly situated in the brain, as shown by the occurrence of Jacksonian epilepsy, 


\section{The Ear}

he thinks the cause must have been a lesion of the central vestibular path or of the compensating apparatus, or, on the other hand, the action of the brain disease upon these parts. The cases were 9 in number, 4 of them being syphilitic; the other 5 were cases of nicotine labyrinthitis, rheumatic facial paralysis, sequelæ of encephalitis, cyst in the cortical motor area and labyrinthitis.

In regard to the pathogenesis, he divides the causes into two groups; first, those in which there is a peripheral neuro-labyrinthine affection which gives rise to the slow nystagmus reaction through an atypical course of compensation; and second, intracranial disease which brings about a lesion or disturbance of the central vestibular routes and the compensation apparatus. He claims attention for this new chapter in nystagmology.

James Dundas-Grant.

\section{Blue Sclerotics and Focal Disease of the Labyrinthine Capsule.} E. Gimplinger. (Zeitschrift für Hals-, Nasen-, und Ohrenheilkunde, Bd. viii., Heft 3, p. 345.)

This is a contribution to the study of the relation of otosclerosis to the general constitution. He describes the post-mortem appearances in cases presenting strikingly blue sclerotics along with deafness. Both labyrinthine capsules showed typical otosclerotic patches; in one ear the footplate of the stapes was ankylosed; in the other its movement was diminished without being completely fixed. Beyond an extreme delicacy of the axis of the cochlea the labyrinths were comparatively normal. Gimplinger concludes that in individuals with otosclerosis there is a constitutional feebleness of the mesenchymal tissue and that the focal disease is only a manifestation coming on through some definite but, as yet, unknown conditions. He reviews the triad of fragilitas osseum, blue sclerotics, and focal disease, i.e. otosclerosis, accredited, in I912, to Adair Dighton. James Dundas-Grant.

\section{The Differential Diagnosis between Labyrinthine Inflammation and Cerebellar Disease. TH. Nuhsmann. (Zentralblatt $f$. Hals-, Nasen-, und Ohrenheilkunde, I925, viii., 201.)}

The author points out that labyrinthitis and cerebellar disease have so many symptoms in common that a labyrinth suppuration occurring in a case of cerebellar abscess is frequently overlooked; to this he attributes the higher death-rate of cerebellar compared with temporosphenoidal abscess. The first and most important sign of labyrinthitis, spontaneous nystagmus to the affected side, is frequently overlooked. The nystagmus to the sound side appears later, and is due to the preponderating influence of the undamaged inner ear. The pointing deviation and falling reactions stand in fixed reciprocal relation to the strength and direction of the nystagmus. 


\section{Abstracts}

The development of a cerebellar abscess is in three stages. First, suppuration breaks through a circumscribed area of dura mater and establishes a focus of encephalitis. The slow progress allows adhesions to form and so checks the onset of a diffuse meningitis. In the second, or latent stage, symptoms are inconspicuous. The signs of an intracranial condition are masked, and must be sought carefully. Changes of mentality are significant, so, too, is deep-seated unilateral posterior headache, increased by flexion of the head. Great importance must be attached to pointing deviations, which may occur in this stage, as also may cerebellar nystagmus. In the third stage the recognised signs appear. The nystagmus is coarser than labyrinthine nystagmus, falling-reaction to the side of the nystagmus is present, and is more violent than the labyrinthine falling. Important also is the low temperature and the disproportionately slow pulse, associated with the increase of intracranial pressure by the growth of the abscess.

In labyrinthine conditions symptoms diminish as the disease progresses, in cerebellar conditions the symptoms steadily advance with the disease.

The author urges the importance of early exploration, and shows that the discovery of an abscess, even when respiratory paralysis has commenced, can be followed by the patient's recovery.

\section{F. W. WatKyn-Thomas.}

Meningitis Serosa with Symptoms like those of Cerebellar Abscess. Georg Boenninghaus. (Zeitsch. für Hals-, Nasen-, und Ohrenheilk., Band xiii., Heft I, p. I.)

In this case an acute labyrinthitis arose in the course of a longstanding middle-ear suppuration, under the stimulus of an inflammation of the tonsils. The radical operation with free opening of the labyrinth was carried out, and a fistula in the external canal was found. Eighteen days later the pulse became slow, and a coarse rolling nystagmus towards the diseased side developed. Cerebellar abscess was suspected, but on exploration none could be found. The dura mater was freely slit as a forlorn hope. Next day the patient brightened up, the symptoms subsided, and the nystagmus slowly disappeared. Much cerebro-spinal fluid escaped into the dressings, and a small prolapse of the cerebellum formed but gradually shrank and the wound was allowed to close. In about a month's time a new prolapse into the meatus was observed in the form of a tense shiny swelling. This arose probably from the pontine cisterna. It could be pressed upwards so as to afford access to the labyrinth from which a sequestrum detached itself and was removed. Subsequently the meningocele burst and liquid kept dropping out. Fortunately no purulent infection 


\section{The Pharynx}

occurred and the opening closed again. The patient resumed his work as a chauffeur, but the ruptures took place again and again which obliged him to give up his occupation. James Dundas-Grant.

\section{THE PHARYNX.}

On the Clinical Features of Peritonsillar Abscess. Gustav Hafer, Vienna. (Zeitschrift fiir Hals-, Nasen-, und Ohrenheilkunde, Bd. xiv., Hefts I and 2, p. 89.)

The writer stresses the importance of a sign for the incision of the abscess, namely, a paresis of the muscles of the soft palate. Its absence led him, in several cases, to withhold incision and speedy recovery followed the spontaneous evacuation of an intratonsillar abscess. In recurrent peritonsillar suppuration the only symptom may be unilateral pain, the cicatricial changes following the previous attacks having led to obliteration of the spaces, the distension of which produces the characteristic bulgings.

James Dundas-Grant.

\section{Serious Hamorrhage following Opening of a Peritonsillar Abscess.}

Norman Patterson. (Lancet, 1926, Vol. i., p. 1256.)

The author describes the case of a woman of 31 , who bled severely for some six days after the evacuation of a peritonsillar abscess. Ligature of the external carotid was performed and, in spite of sepsis, resulted in a good recovery. Macleod Yearsley.

The Technique of Adeno-Tonsillectomy. James C. G. McNaB, M.D., F.R.C.S.Ed. (Brit. Med. Journ., 6th February 1926.)

This is a short review of the methods of operation most frequently in use at the present time, with the author's predilections definitely stated. He believes that after the age of 5 years nearly all tonsils are useless and a source of danger. In children he uses ethyl chloride anæsthesia and a guillotine with single blade. He does not find that the crushing blade reduces hæmorrhage, and it is more frequently followed by the loss of the anterior pillar, although this misfortune may occur by any method. Ninety-five per cent. of tonsils can be completely enucleated by the blunt guillotine, and he found that even the remaining 5 per cent., consisting of the small adherent tonsil, the long flat tonsil, and the adherent tonsil stumps left after previous operations, can be reduced to $\mathrm{I}$ per cent. by following accurately Sluder's technique. Patients coming between the ages of I $3_{3}$ and I $_{7}$ years are anæsthetised with ether and oxygen, and the locked guillotine is retained in position for three minutes. Should there be any oozing the enucleated tonsil is fixed on a volsellum, cleansed with iodine, and replaced firmly in the tonsil bed for two minutes. The adenoids

voL. XLI. NO. XI. 


\section{Abstracts}

are removed by Kelly's direct-vision adenotome. Beyond the age of 18 years, he prefers local anæsthesia, the dissection being carried out by means of curved scissors and a strip of gauze, avulsion being effected by a Lermoyez snare. The patient is kept under the influence of morphine for twenty-four hours. Every case, whether child or adult, should be kept under observation for from six to twelve weeks.

\section{T. Ritchie RODGER.}

\section{Prolonged Hamorrhage with Normal Coagulation and Bleeding Time.} James G. Callison. (Laryngoscope, No. 5, Vol. xxxiv., p. 354.)

A male, aged $\mathrm{r} 9$, was admitted for a tonsil and adenoid operation. The history obtained after the operation showed that there was hæmorrhage from the umbilicus at birth and another hæmorrhage after circumcision. When ten years old, he had an attack of "rheumatism." Wassermann reaction was negative, as also physical examination. When about to be operated on, the patient volunteered the statement that he was a bleeder, so his coagulation and bleeding times were tested, which were eight and six minutes respectively. As these were normal, the operation was undertaken. There was free bleeding during the operation, unusually difficult to control. $\mathrm{He}$ was given $\frac{1}{4}$ grain of morphine, and as he had had one-sixth of a grain before operation, this made a total of five-twelfths of a grain. About two hours after, the patient bled freely, and 20 c.c. of $3 \circ$ per cent. solution of sodium citrate were given intravenously. Two hours later the patient was cyanotic, the respirations spasmodic, pupils pinpoint, and he was bleeding freely from the right tonsillar fossa. It was controlled by pressure, but recurred on removal. Finally two sponges were placed in the fossa and the pillars stitched. During the night, there was slight oozing and this became profuse about noon. Sodium citrate was again injected, but without effect. Hypodermoclysis of 500 c.c. physiological saline was given and a Murphy drip ordered-this, however, could not be given, as fresh blood blocked the rectal tube; there was probably bleeding from the intestinal tract. A little later, 20 c.c. of horse serum were given subcutaneously. This seemed to control the bleeding in one and a half hours. The patient was a type III, and it was necessary to accept a type IV donor for the emergency. $\mathrm{He}$ received 500 c.c. of blood by the citrate method, and a chill lasting twelve minutes followed.

On the third day, no bleeding, sponges removed, considerable odour, and one sponge was overlooked for a time. On the fourth day, no bleeding, but clot reformed. On the fifth day, free bleeding from the same area. On the sixth day, another 500 c.c. citrated blood were transfused. On the seventh day, a large clot and the forgotten sponge were removed. Severe bleeding occurred later in the day. 


\section{The Pharynx}

On the eighth day, patient again bled profusely, this time from the left tonsillar fossa. Horse serum was given intravenously. On the ninth day, 500 c.c. citrated blood were transfused. On the tenth day bleeding was so profuse during the night that the condition seemed hopeless. The tonsillar fossa failed to show the usual post-operative contraction. Hypodermic injections of a soluble thyroid-pituitaryspermin preparation and five minims of adrenalin were given every three hours. From now on, there was a rapid improvement, though healing in the tonsillar fossæ was backward. Brines claims that citrate destroys the blood platelets and so retards coagulation of the blood. The facts of this case seem to bear out this claim, especially as the patient showed an increased tendency to bleed at each transfusion.

In the author's opinion the patient was a sporadic bleeder of undetermined type, possibly a type not yet described specifically. The patient was neither purpuric nor hæmophilic; he bled for eleven days in the presence of a normal coagulation and bleeding time and of immediate clotting on exposure to the air.

\section{Andrew Campbell.}

\section{Pseudo-Phlegmonous Peritonsillitis. E. Escat. (L'Oto-Rhino- Laryngologie Internationale, April 1925, p. 193.)}

The point under discussion is: Given a peritonsillitis with the clinical characters of a quinsy, how does one explain spontaneous resolution without suppuration? This may be explained by one of the following eight conditions :-

(I) A true abortive peritonsillitis: All inflammatory processes which have not passed a critical point may resolve without suppuration, and it has long been recognised that this may take place with a peritonsillitis, but this is an exceptional event.

(2) Peritonsillar abscess with concealed spontaneous evacuation: Although the bursting of a peritonsillar abscess is usually evident to the patient, it may escape observation and the rupture may take place under the anterior pillar or on the nasopharyngeal surface of the soft palate and thus be undetected.

(3) A subacute mucocele of the supratonsillar fossa: This condition may give rise to the appearances of quinsy. During the course of a catarrhal tonsillitis, often mild in character, dysphagia increases and swelling of the soft palate takes place, but these symptoms subside with gradual escape of seromucous discharge from the fossa over the top of the tonsil. Probing of the fossa may sometimes relieve these cases. 


\begin{abstract}
s
(4) Simple tonsillitis occurring in buried tonsils: A simple tonsillitis involving the upper pole may stimulate a peritonsillitis, particularly in individuals in whom the plica triangularis is well developed and in whom, as a result, the upper pole is abnormally buried.

(5) Encysted caseous tonsillitis of the upper pole: In a simple chronic tonsillitis, swelling may shut off septic material in a crypt and produce a condition resembling a quinsy.

(6) Periostitis of the internal surface of the inferior maxilla: This condition, resulting from dental sepsis, may somewhat simulate a true peritonsillitis.

(7) Diphtheria of the supra-tonsillar fossa is rare as an isolated condition, but when present, simulates a peritonsillitis.

(8) An acute pharyngitis.
\end{abstract}

A. J. WRight.

\title{
MISCELLANEOUS.
}

Speech Defects and the Noise Apparatus. G. A. WeILl. (L'OtoRhino-Laryngologie, May 1925, p. 260.)

Functional aphonia can usually be cured eventually by some contra-suggestion. The method here described depends essentially on removing auto-suggestion. Following some emotion or a catarrhal attack, aphonia takes place. The patient hears himself speak, and owing to this auditory auto-suggestion, aphonia becomes established, even when the cause has disappeared. With a noise apparatus, one can suppress the acoustic control and thus cut out temporarily the auto-suggestion. The most suitable instrument is the apparatus of Lombard, in which the noise produced electrically is conveyed to either ear by telephonic means. The method consists in instructing the patient to read out loud as distinctly as possible. When he has begun, the noise apparatus is switched on and little by little the voice of the reader becomes louder. The noise is then suddenly stopped, the patient hears himself talk, and the spell is broken.

A. J. WRight.

Paralysis of the Ten Last Cranial Nerves by a Cylindroma. A. SARGNON and MAYoux. (L'Oto-Rhino-Laryngologie Internationale, October 1925 , p. 545.)

Symptoms had been present for six months in a woman aged 46 . These symptoms arose in the following order; firstly, a swelling of the glands in the left side of the neck, followed one month later by difficulty in swallowing with a return of fluid through the nose. Two months later, progressive loss of voice took place, with rapid wasting 776 


\section{Reviews of Books}

resulting from the difficulty in swallowing. Examination showed, in addition to the mass of glands in the neck, paralysis of all the cranial nerves on the left side with the exception of the first and second. Palpation of the nasopharynx showed a hard granular mass in the neighbourhood of the left Eustachian tube. A fragment examined histologically showed the growth to be a cylindroma. The ninth to the twelfth cranial nerves inclusive were probably paralysed by the secondary glands and the remainder by the primary growth. Emphasis is laid on the relative frequency of these peritubal growths and on the difficulty of their diagnosis. An unexplained deafness is usually the first symptom.

A. J. WRIGHT.

\section{REVIEWS OF BOOKS}

Points in the Diagnosis and Treatment of Tuberculosis and Cancer of the Larynx. By Sir James Dundas-Grant, K.B.E., F.R.C.S. London: H. K. Lewis \& Co., Ltd., I926. Price Is. 6d.

This lecture, delivered before the Fellowship of Medicine and reprinted from the Clinical Journal, is something more than its modest title implies, for it is an admirable exposé of a subject full of difficulties from a clinical standpoint, and at times one of the most baffling in laryngology. It is written in language which can be readily understood by the general practitioner and is valuable to the specialist as an expression of the author's rich clinical experience.

The principles underlying diagnosis are well brought out and enforced by histories of carefully chosen cases freed from unnecessary detail. Within the compass imposed upon him, the author gives us an account of treatment which could not be improved upon. It is eminently practical, and, in the case of laryngeal tuberculosis, it opportunely reminds us of, what is too often overlooked, the great value of medication in the relief of some of the most distressing symptoms of a painful disease.

The little book contains a number of helpful illustrations and ends with a summary and conclusions which embody the author's mature views upon problems which he has done so much to elucidate.

D. R. Paterson.

Contributions to the Art and Science of Otology: Lectures and Papers. By Richard LaKe, F.R.C.S., I892-1925. London: Macmillan \& Co. Price $\mathbf{r}_{5}$.

This book is a small volume of 255 pages, briefly and concisely written, and is a collection of papers published at various times by the author. It is a valuable piece of work, possessing the advantages 